\title{
Antecedents and consequences of stress in retailing: environmental expectations and promoter scoring
}

\section{Laura Lucia-Palacios, Raúl Pérez-López and Yolanda Polo-Redondo Department of Marketing, University of Zaragoza, Zaragoza, Spain}

\begin{abstract}
Purpose - The aim of this paper is to examine the effects of the disconfirmation of expectations of crowding and mall accessibility, on stress and two marketing outcomes, satisfaction and promoter scoring.

Design/methodology/approach - Data were obtained through two face-to-face surveys from mall shoppers that answered them at two different moments of their shopping experience, before entering the mall and before leaving it. Results are obtained from 230 customers that answered the two questionnaires.

Findings - The findings suggest that stress indirectly influences customer promoter scoring through satisfaction, while disconfirmation of expectations influences it directly and indirectly.

Practical implications - These results also suggest that stress and disconfirmation of expectations about crowding and accessibility are important in determining promoter scoring. To reduce stress and increase satisfaction and promoter scoring, managers should focus on exceeding customers' expectations about mall accessibility and on ensuring that customers experience a lower level of crowding than they expected.

Originality/value - The article examines Net Promoter Scoring, an outcome that has attracted managers' attention but little is known about its antecedents. The paper provides evidence of the effect of disconfirmation of expectations and negative emotions on promoter scoring.
\end{abstract}

Keywords Promoter scoring, Stress, Disconfirmation of expectations, Crowding, Accessibility

Paper type Research paper

\section{Introduction}

Previous research has focused on how to create positive emotions in retailing; however, it might also be useful to study the dark side of the shopping experience and try to identify the environmental elements that create negative consumer feelings during shopping, because negative feelings can also influence consumers' responses and behaviour, such as by increasing dissatisfaction, purchase abandonment and negative word-of-mouth (WOM) (Albrecht et al., 2017; Lessassy, 2019; Lucia-Palacios et al., 2020; Rosenbaum et al., 2016; Uhrich and Tombs, 2014). Stress is one of the most common negative feelings experienced by shoppers. Stress occurs when a person is overwhelmed by a situation or event (Moschis, 2007), and it entails affective, physiological and behavioural responses. A review of retailing research on stress reveals that most articles have focused on examining its main causes. Crowding or parking difficulties are two of these causes (Demoulin and Willems, 2019; LuciaPalacios et al., 2018; Baker and Wakefield, 2012), but little is known about how the disconfirmation of expectations of these mall environmental characteristics may impact on stress or its consequences. Therefore, this research will examine the impact of disconfirmation of expectations of mall's crowding and accessibility on customer stress during the shopping experience.

Furthermore, stress in the shopping context has attracted much attention because of its impact on purchasing decisions, store abandonment or re-patronage intentions (Albrecht et al., 2017; Baker and Wakefield, 2012; Grzeskowiak et al., 2016; Lucia-Palacios et al., 2020;

The authors wish to thank the support received by the Government of Spain (project ECO2017-83993-P and ECO2014-54760) and the Government of Aragón and the European Social Fund (GENERES Group S-54_17R).

Received 30 March 2020

Revised 12 April 2020 25 September 2020 Accepted 10 December 2020 
Maier and Wilken, 2014). However, to the best knowledge of the authors, there has been limited research on the consequences of stress on satisfaction or on any measure related to loyalty or recommendation (Rychalski and Hudson, 2017). The Net Promoter Score (NPS) proposed by Reichheld (2003) has become an increasingly popular method for firms to measure customer loyalty (Maddox, 2007; Raassens and Haans, 2017; Mecredy et al., 2018), as it is based on a single question that measures the customer's intention to recommend the company to friends or colleagues. This divides the customers into promoters, satisfied customers or detractors. A promoter is a person that will speak positively about the product or brand in a proactive way. This will attract new customers and reaffirm the brand image, so researchers have paid attention to how to convert customers into promoters or advocates of a firm (Fierro et al., 2014). Previous research about NPS has focused on its relationship with different firm performance metrics, such as profitability, sales or market share, and it has been compared to other loyalty measures (Bendle and Bagga, 2019; Van Dorn et al., 2013; de Haan et al., 2015). However, little attention has been paid to the antecedents of this performance metric. Research is, therefore, needed to examine the stress-satisfaction and stress-promoter scoring relationship.

The preceding discussion shows that it should be interesting, first, to examine whether the disconfirmation of expectations of crowding and accessibility influences stress; second, to analyse the relationship between stress, satisfaction and promoter scoring and third, to examine the possible mediation effect of stress between disconfirmation of expectations and the two outcomes of satisfaction and promoter scoring.

To meet these objectives, a two-part questionnaire about the shopping experience was carried out through a face-to-face mall intercept method. The first part was answered before shoppers entered the shopping centre, and the second part just after they had left it. In the first part, we asked about expectations; in the second part, we asked about perceptions. The same individuals responded to the two parts of the questionnaire, so the information can be used to calculate the disconfirmation of expectations.

Our research contributes to the marketing literature and retail research by providing evidence of the effect of stress on two customer outcomes: satisfaction and promoter scoring. The results suggest that not all customer emotional responses may affect customer behaviour in the same way. The paper also contributes by examining the effect of disconfirmation of expectations of a mall's crowding and accessibility as antecedents of stress and by investigating the mediating role that stress has on satisfaction and promoter scoring. The results suggest that stress acts as a mediator between disconfirmation of expectations and satisfaction, but that it is not a mediator between disconfirmation of expectations and promoter scoring. These results have implications for mall managers in relation to the reduction of customers' stress and the improvement of promoter scoring.

Section 2 presents the theoretical background of the study and the hypotheses. Section 3 explains the research methodology, and Section 4 presents the results. We conclude with a discussion of the main results, the managerial implications and suggestions for future research.

\section{Conceptual model development and hypotheses}

The inclusion of emotions in the study of customer satisfaction and loyalty is critical for experiential services and is a hot topic in marketing. Based on the cognitive theory of emotions (Bagozzi et al., 1999; Das and Varshneva, 2017; Demoulin and Willems, 2019; Elmashhara and Soares, 2019), disconfirmation of expectations has a direct effect on emotions, while at the same time emotions act as mediators between the cognitive part of the customer experience and the final customer behaviour. This theory is used to propose the hypotheses of the current study and the model that is tested (Figure 1). 


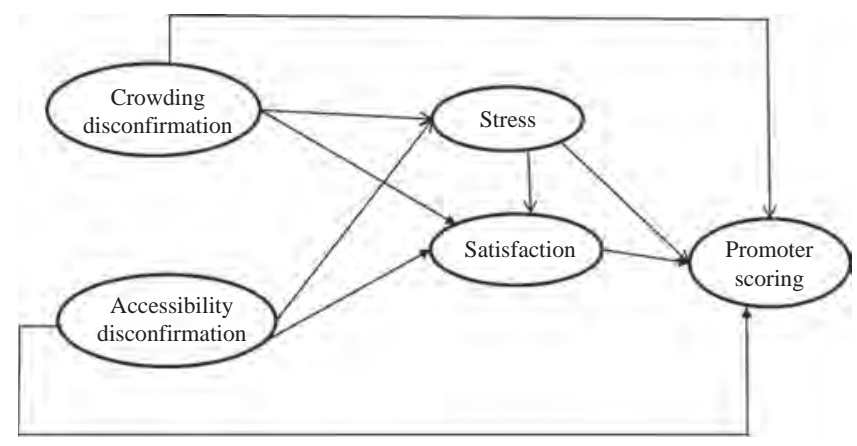

Stress in retailing

Figure 1. Theoretical model

\subsection{Disconfirmation of expectations and stress}

Disconfirmation of expectations usually means that service performance falls short of (exceeds) what a consumer expected when making a purchase decision, with negative (positive) implications for the service experience. In a retail setting, a customer may have expectations about different aspects of the experience. In this research, we analyse expectations about mall accessibility and crowding. These retail elements influence the customer's experience, are sources of stress (Kim and Runyan, 2011; Santini et al., 2020; Soars, 2009; Van Rompay et al., 2012), and may differ from one visit to another to the same mall. Of these aspects, crowding is the most analysed element in retailing.

Crowding is a social factor that leads to feelings of discomfort and irritation during the shopping activity and reduces satisfaction, time spent in the store and repatronage intentions (Knoeferle et al., 2017; Park and Zhang, 2019; Pons et al., 2016; Santini et al., 2020; Roozen, 2019; Van Rompay et al., 2012). Hui and Bateson (1991) showed that perceived crowding in retailing affects consumers' emotional responses and their desire to stay in the facility and that it creates negative feelings. These negative consequences are because crowding increases shopping time, reduces the availability of products and shop assistants and increases time spent queuing (Sujan et al., 1999; Van Rompay et al., 2012). One of the main direct outcomes of crowding is stress (Lucia-Palacios et al., 2018). Similar conclusions have been reached in retail research that has focused on perceived crowding and stress (Baker and Wakefield, 2012; Eroglu et al., 2005).

Although previous research has analysed the effect of perceived crowding on stress, finding a positive relationship (Baker and Wakefield, 2012; Lucia-Palacios et al., 2018), our study examines the effect of disconfirmation of crowding expectations on emotions. We propose that an unexpected level of crowding will influence customer emotional response. Therefore, we hypothesize:

H1. Positive disconfirmation of expectations about crowding (perceived crowding is higher than expected) will have a positive effect on stress.

Time is one of the most valuable assets for the contemporary consumer, so the link between time and shopping is of great interest in the study of consumer behaviour. Mall accessibility refers to the time and effort involved in getting to and leaving the mall by car, taxi or bus, as well as in moving inside the mall from one store to another (Hart et al., 2007; Reimers and Chao, 2014). Thus, accessibility refers to the customers' perceptions of mall location, mall design, parking convenience and the mall's connections with main roads. Traffic congestion management is an important means of saving travel time and leads to customer satisfaction (Ibrahim and Ng, 2002; Park and Zhang, 2019). Furthermore, looking for a place to park involves a cost in terms of time, so a well-signposted car park is an important managerial cue 
(Van Ommeren et al., 2012). Negative disconfirmation of expectations about accessibility can trigger negative emotional responses (Smith, 2005; Sujan et al., 1999), such as stress, due to an increase in travel time, traffic jams, difficulties in finding a parking space, difficulties in accessing the mall because it is located in a part of city that is difficult to reach by car or public transport or the complexity of moving from one part of the mall to another. So, we propose:

H2. Positive disconfirmation of expectations about mall accessibility (perceived accessibility is better than expected) has a negative effect on stress.

\subsection{Stress, satisfaction and promoter scoring}

Satisfaction is a state of a consumer's mind that shows the consumer likes or dislikes the service after experiencing it (Mahmoud et al., 2018). Although satisfaction is a prerequisite for loyalty, previous research has suggested that something else is required to lead to repeat purchases and to create loyalty (Kumar et al., 2013). Although some discrepancies are found when this relationship is analysed, most previous research has found that higher overall satisfaction is related to a higher propensity to recommend (Bedi, 2010; Kaura, 2013; Sivadas and Baker-Prewitt, 2000; Wilson et al., 2012). Since promoter scoring is a measure of loyalty that implies active recommendation, we propose:

H3. Satisfaction will have a positive influence on promoter scoring.

Most previous research has found that emotions such as pleasure and arousal are related to satisfaction in different contexts (De Rojas and Camarero, 2008; Ladhari, 2009; Raassens and Haans, 2017; Walsh et al., 2011). However, the stress-satisfaction link has attracted much less attention and little is known about it. Singh and Duque (2012) examined this relationship in a police context and found a negative relationship. Lucia-Palacios et al. (2020) found that stress worsens mall experience. Since stress is a negative emotional response, we expect that it will decrease customer satisfaction. The link between emotions and loyalty is robust in different contexts (Bigné et al., 2008; Ou and Verhoef, 2017; Walsh et al., 2011). Previous research has found that positive emotions influence loyalty (Bigné et al., 2008) and positive WOM(Ladhari, 2007). Similarly, negative emotions (such as anger, frustration, distress, disgust, boredom or regret) reduce that behaviour (Chen et al., 2015; Liu and Jang, 2009; Peng et al., 2017; Saintives and Lunardo, 2016). Others have found a positive relationship between positive emotions and positive WOM (White and Yu, 2005). So, we propose:

H4. Stress will have a negative influence on (a) satisfaction and (b) promoter scoring.

\subsection{Mediation effect of stress}

To consider a mediation effect of stress, first there should be a relationship between disconfirmation of expectations and the two outcomes of satisfaction and promoter scoring. Consistent with the expectancy disconfirmation paradigm (Dai et al., 2020; Gillison and Reynolds, 2018; Qazi et al., 2017; Oliver and Westbrook, 1993), when service perceptions exceed expectations, a positive disconfirmation is created that results in increasing satisfaction. So, a positive disconfirmation would lead to a positive consumer satisfaction and vice versa (Bigné et al., 2008; Caro and García, 2007; Dai et al., 2020; Liu et al., 2020). Similarly, some studies have found a positive and direct effect of disconfirmation of expectations on loyalty or intentions to intensify the service usage (Caro and García, 2007). The literature indicates, therefore, that disconfirmation of expectations can have a direct influence on satisfaction and promoter scoring. Thus, we propose:

H5. Positive disconfirmation of expectations about crowding will have a negative influence on (a) satisfaction and (b) promoter scoring. 
H6. Positive disconfirmation of expectations about accessibility will have a positive influence on (a) satisfaction and (b) promoter scoring

According to the cognitive-affective model, there is evidence of the mediation effect of emotions between the stimuli the consumers receive in the retail environment and the consumers' behaviour. Mehrabian and Russell's (1974) model suggests that emotions are mediators between stimuli, the cognitive process and behaviour. The mediating role of emotions between disconfirmation of expectations and satisfaction has been widely tested and confirmed in the literature (Bigné et al., 2008; Caro and García, 2007; Das and Varshneva, 2017; De Rojas and Camarero, 2008; Elmashhara and Soares, 2019; Lucia-Palacios et al., 2016; Morrison et al., 2011; Qazi et al., 2017). Similar results have been found when loyalty or recommendations are examined as customer behaviour (Chen et al., 2015; DeWitt et al., 2008; Jang and Namkung, 2009). Furthermore, stressful situations can create an emotional reaction that can in turn affect behaviour (Baker and Wakefield, 2012; Hampson and McGoldrick, 2017; Harris and Fleming, 2017). Therefore, stress may mediate the effect of disconfirmation of expectations on satisfaction and promoter scoring. Hence, we propose:

H7. Stress will mediate the relationship between satisfaction and disconfirmation of expectations (a) about mall crowding and (b) about accessibility.

H8. Stress will mediate the relationship between promoter scoring and disconfirmation of expectations (a) about mall crowding and (b) about accessibility.

\section{Methodology}

Data were obtained through a two-part face-to-face survey conducted over two weeks in October and November 2014 in a shopping centre located in the north-east of Spain. This mall is currently the largest shopping centre in Spain and received the MAPIC 2013 award for the world's best shopping and leisure development.

The questionnaire was administered by two interviewers, at two different moments of the shopping experience, and at the two entrances to the commercial gallery of the mall, which allowed us to record the participants' perceptions and emotions while they were experiencing them (Lemke et al., 2011). First, the interviewers approached mall visitors just before they entered the shopping centre; for the second part of the survey, the participants were approached at the end of their shopping experience, just after they had left the shopping centre. In this way, data were collected from the same customers at two different moments, allowing us to avoid the common method bias (Polites and Karahanna, 2012). The participants were informed about the anonymous character of the interviews when they approached at the entrance to the mall in order to reduce the possibility of them answering our questions dishonestly. Furthermore, they were offered two free drinks as a reward for their participation. We intercepted 264 mall shoppers, 231 of whom answered the two parts of the questionnaire and 230 questionnaires were valid. Table 1 presents the sample's characteristics of age, gender and frequency of visits to shopping centres. As the table shows,

\begin{tabular}{|c|c|c|c|c|c|c|}
\hline \multicolumn{2}{|l|}{ Age $(\%)$} & \multicolumn{2}{|c|}{ Gender (\%) } & \multicolumn{2}{|c|}{ Frequency of visit (\%) } & \\
\hline 18-25 & 35.5 & Women & 70.1 & $<$ once/month & 6.93 & \\
\hline $26-45$ & 52.4 & Men & 29.9 & $2-3$ times/month & 45.45 & Table 1. \\
\hline $45-64$ & 11.3 & & & $4-5$ times/month & 31.60 & Description of the \\
\hline$\geq 65$ & 0.9 & & & $>5$ times/month & 16.02 & sample \\
\hline
\end{tabular}


the respondents were mainly women between 18 and 45, and they visit the shopping centre between one and four times a month.

\subsection{Variables}

Promoter scoring is a variable based on the NPS proposed by Reichheld (2003). It was determined by one question related to the likelihood of recommendation: "Can you indicate how likely it is that you would recommend 'this firm/brand' to a friend or colleague? $(0=$ not at all likely, 10 = extremely likely)". Satisfaction was measured with three items on a sevenpoint Likert scale based on previous research (Mattila and Wirtz, 2001; Westbrook and Oliver, 1981).

Stress is a construct that consists of five indicators measured on a seven-point Likert scale following previous research (Baker and Wakefield, 2012).

Disconfirmation of expectations was calculated as the difference between perceptions and expectations. Previous research has recommended implementing this subtractive approach to measure disconfirmation directly (Pitt et al., 1995; Swan and Trawick, 1980). Consumers were asked about their expectations at the time of entering the mall, then, before leaving, they were asked about their perceptions with respect to crowding, search cost, and mall accessibility. These aspects were measured using a seven-point Likert scale.

Crowding is a construct that consists of eight items based on previous research (Baker and Wakefield, 2012; Eroglu et al., 2005; Machleit et al., 2000). Similarly, mall accessibility consists of four items that are based mainly on the findings of Ibrahim and $\mathrm{Ng}(2002)$ and have been adapted from Hart et al. (2007) and Kim et al. (2014). Customers gave their opinions about these aspects both as expectations and as perceptions. The values of the disconfirmation of expectations variable were between -6 (completely negative disconfirmation of expectations) and 6 (complete positive disconfirmation of expectations). A value of 0 indicates an exact match between expectations and perceptions. Because of this range of values, these constructs have been re-scaled on a seven-point Likert scale (see Table 2).

The Appendix presents a summary of the constructs and measures used for this study. The questionnaire also included other control variables, such as the frequency of the customer's visits to the mall and the day of the week. Frequency was a categorical variable following the classification of Table 1 . A variable called "weekend" was created and included as a dummy variable that takes a value of 1 for questionnaires obtained on Friday afternoons and Saturdays and 0 for questionnaires obtained from Monday to Friday morning.

\subsection{Common method bias and unobserved heterogeneity}

A common method bias may result in serious problems. Harman's one-factor test was conducted, and we found that a single factor explained $29.9 \%$ of the variance, whereas, when considering the five factors of the model, the variance explained increased to $75.97 \%$. Thus, the data does not have a common method variance problem. This problem was minimized because the data were collected at two different moments.

Unobserved heterogeneity may create biased results if the data contains groups that are latent. Latent class techniques were applied to identify and treat unobserved heterogeneity (Rigdon et al., 2011; Ringle et al., 2010; Sarstedt and Ringle, 2010). FIMIX-PLS (Finite Mixture Partial Least Square), a method to test the homogeneity of the sample, was applied. Results

Table 2.

Rescaling of the measure perceptionsexpectations

\begin{tabular}{lccccccr}
\hline New scale & 1 & 2 & 3 & 4 & 5 & 6 & 7 \\
\hline Perceptions minus expectations & $-6,-5$ & $-4,-3$ & $-2,-1$ & 0 & 1,2 & 3,4 & 5,6 \\
\hline
\end{tabular}


suggest that there were no problems of unobserved heterogeneity because, when the software tried to create two groups, one of them became too small to have the entity of a group. We concluded, therefore, that the sample complies with the homogeneity assumption.

\section{Results}

\subsection{Descriptive results}

According to Reichheld (2003), customers can be divided into promoters of the firm, satisfied customers and detractors of the firm, depending on their scores in the NPS: 9-10 for promoters, $6-8$ for satisfied customers and 5 or less for detractors. Our results show that 145 customers were promoters, 73 were satisfied customers and 9 were detractors. In our sample, the greatest proportion of customers is found in the group of promoters, so the sample is biased towards this type of customer. Only five percent were detractors. This was an expected result, as the selected shopping mall won the award for the world's best shopping and leisure development.

\subsection{Measurement of construct validation}

An exploratory factor analysis using varimax rotation in Statistical Product and Service Solutions (SPSS) was carried out to check the unidimensionality of all the constructs. Scales were purified. Since loadings for four of the eight items of crowding disconfirmation were below 0.6 , these items were eliminated together with one item of stress and another of accessibility disconfirmation. After eliminating these, the Cronbach's alpha and average variance extracted (AVE) values improved for these constructs. Table 3 shows that the rest of the factor loadings are above 0.6 (Carmines and Zeller, 1979), and that the AVE is above 0.5 (Hair et al., 2015). The reliability of the indicators for the reflective constructs was assessed

\begin{tabular}{lccccc}
\hline Items & Factor loadings & Cronbach`s alpha & Rho_A & AVE & Composite reliability \\
\hline Satisfaction & & 0.93 & 0.94 & 0.88 & 0.95 \\
Sat_1 & 0.91 & & & \\
Sat_2 & 0.95 & & & \\
Sat_3 & 0.96 & 0.92 & 0.80 & \\
Stress & Eliminated & & & \\
Stress_1 & 0.93 & & & \\
Stress_2 & 0.94 & & & \\
Stress_3 & 0.93 & & & \\
Stress_4 & 0.77 & & & \\
Stress_5 & 0.91 & & \\
Crowding (dis) confirmation & Eliminated & & & \\
CEC_1 & 0.81 & & & \\
CEC_2 & Eliminated & & & \\
CEC_3 & 0.88 & & & \\
CEC_4 & Eliminated & & & \\
CEC_5 & 0.94 & & & \\
CEC_6 & Eliminated & & & \\
CEC_7 & 0.91 & & & \\
CEC_8 & Eliminated & & & \\
Accessibility (dis) confirmation & 0.86 & & & \\
CEA_1 & 0.72 & & & \\
CEA_2 & 0.77 & & & \\
CEA_3 & & & \\
CEA_4 & & & & \\
& & & & \\
\end{tabular}

Table 3.

Validation of measurement constructs 
through Cronbach's alpha, whose values should exceed a minimum value of 0.7 (Hair et al., 2015; Nunnally, 1978)

Table 4 compares the square roots of the AVE (diagonal values) with the correlations between the reflective constructs. The results suggest that the measurement model was adequate in terms of discriminant validity. Additionally, we have calculated the heterotraitmonotrait (HTMT) ratio as another measure of discriminant validity (Table 4). All the values are below the threshold of 0.85 (Henseler et al., 2015).

\subsection{Hypotheses testing}

SmartPLS 3 software (Ringle et al., 2015) was used to assess the structural model, and the partial least squares (PLS) consistency estimation was used. Figure 2 shows the results of the conceptual model with the significant path coefficients. In PLS estimation, there is no global criterion that allows us to evaluate the overall model. The communality value measures the capacity of the manifest variable to describe the related latent variable. In this research, this measure ranged from 0.2 to 0.6 . To test predictive relevance, the software provides the $Q^{2}$ (Stone, 1974; Geisser, 1974). Models with positive $Q^{2}$ values have high predictive relevance. All the endogenous constructs show positive values for the $Q^{2}$ test (Table 5). Although the $Q^{2}$ test is adequate for testing the goodness-of-fit for reflective constructs, its value should be treated with caution for the promoter scoring variable because promoter scoring is a singleitem construct. Other fit values of the estimated model are the value of standardized root mean square residual (SRMR) that is 0.051; chi square value is 304.491 and the NFI (normed fit index) is 0.948 . These values indicate a good fit of the model.

Figure 2 shows the results of the structural model. According to the results, positive disconfirmation of expectations about crowding has a positive effect on stress, supporting H1. Positive disconfirmation of expectations about accessibility has a negative and significant effect on stress, supporting H2. Satisfaction has a positive and significant effect on promoter scoring, supporting H3. Stress has a negative and significant effect on satisfaction, but it has a non-significant effect on promoter scoring; so, H4a is supported but H4b is not. To understand the non-significant effect of stress on promoter scoring, a mediation effect was examined following the methodology of Preacher and Hayes (2008) (see Tables 6-8). Stress has no direct effect on promoter scoring, but this is due to the total mediating effect of satisfaction.

Hypotheses 5 and 6 are related to the effects of disconfirmation of expectations on satisfaction and promoter scoring. The results show that disconfirmation of expectations about crowding impacts negatively on promoter scoring but not on satisfaction, supporting H5b but not H5a. However, positive disconfirmation of expectations about accessibility has a positive effect on satisfaction and on promoter scoring, so H6a and H6b are supported. Finally, a mediation effect of stress between the cognitive stimuli and customer behaviour is proposed. According to the results (see Tables 7 and 8), stress totally mediates the

Table 4.

Discriminant validity

\begin{tabular}{lcccrr}
\hline & disc_access & disc_crowd & Promoter & Satisfaction & Stress \\
\hline Accessibility disconfirmation & 0.783 & 0.253 & 0.113 & 0.468 & 0.186 \\
Crowding disconfirmation & -0.198 & 0.884 & 0.158 & 0.133 & 0.233 \\
Promoter scoring & 0.120 & -0.152 & 1.000 & 0.531 & 0.196 \\
Satisfaction & 0.404 & -0.127 & 0.513 & 0.939 & 0.319 \\
Stress & -0.161 & 0.266 & -0.194 & -0.302 & 0.896
\end{tabular}

Note(s): Diagonal and in italics: Squared roots of AVE, Below diagonal: Correlations between variables. Above diagonal: HTMT ratio values 


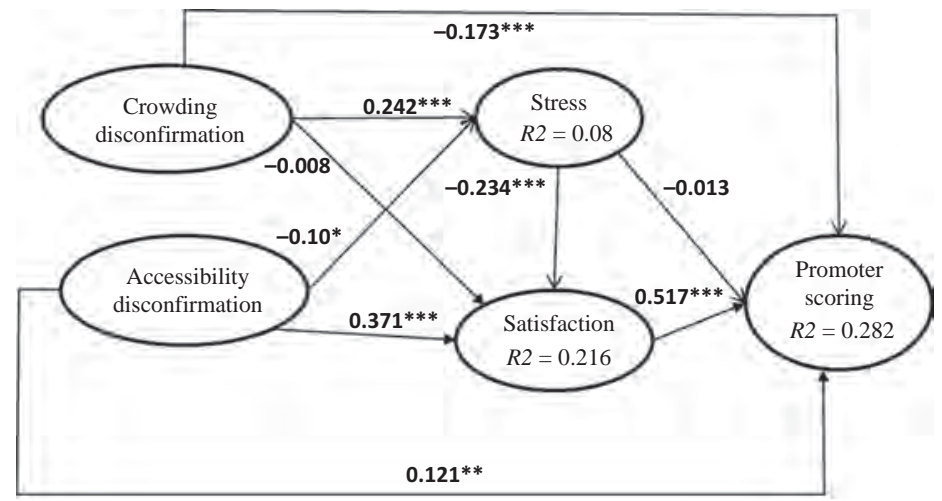

Note(s): ***significant at 0.001 level; **significant at 0.05 level and *significant at 0.10 level
Stress in retailing

Figure 2.

Structural results

\section{Dependent variables}

Promoter scoring

Satisfaction

Stress

Communality

1.0

0.660

0.547
Redundancy $\left(Q^{2}\right)$

0.253

0.202

0.058
Table 5.

Goodness-of-fit measures
Total effect

Direct effect of IVs

Promoter scoring

\begin{tabular}{llll}
\hline Stress & $-0.148^{* *}$ & -0.02 & Total effect \\
Satisfaction & & $0.554^{* * * *}$ & Satisfaction
\end{tabular}

Indirect effect

BC 95\% confidence interval Indirect effect Low Upper

$\begin{array}{lll}-0.126 & -0.211 & -0.056\end{array}$
Table 6.

Mediation effect of satisfaction between stress and promoter

Note(s): ***significant at 0.001 level; ** significant at 0.05 level; *significant at 0.10 level scoring

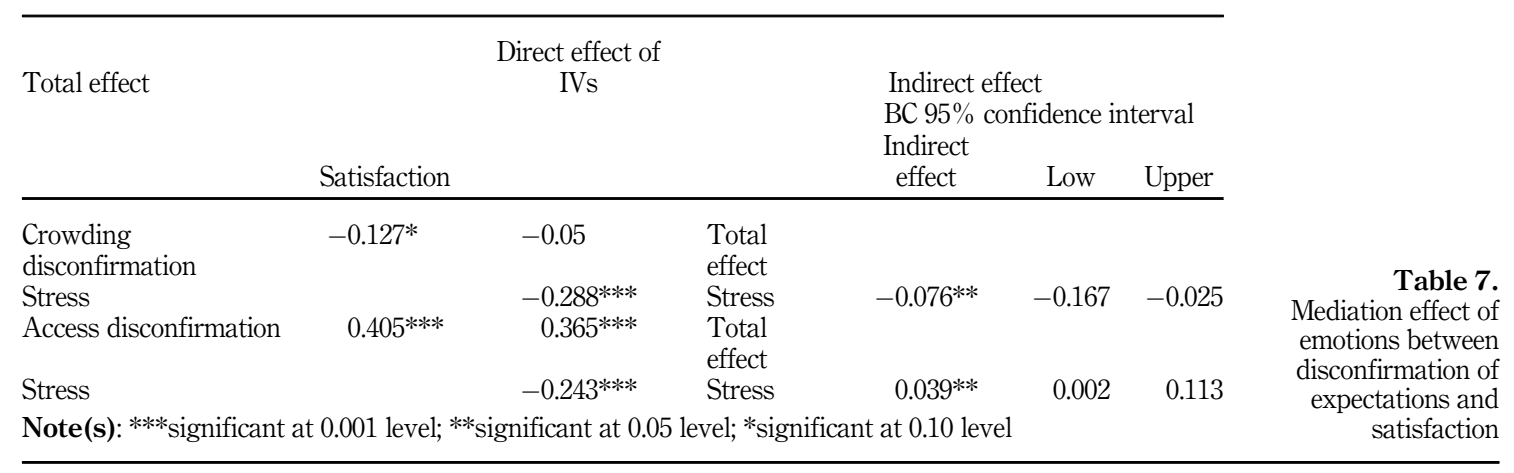


relationship between satisfaction and disconfirmation of expectations about crowding, and it partially mediates the relationship between satisfaction and disconfirmation of expectations about accessibility, so H7a and H7b are supported. Related to the possible mediation effect of stress between disconfirmation of expectations and promoter scoring, the results show that stress does not exert any mediation effect, so hypotheses H8a and H8b are not supported. In the relationship between promoter scoring and disconfirmation of expectations, satisfaction is the aspect that exerts a mediating role. In this case, satisfaction exerts a partial mediation between disconfirmation of expectations about crowding and accessibility on promoter scoring. So, the final path seems to be the following: disconfirmation of expectations about crowding and accessibility directly influences promoter scoring and additionally generates stress that influences promoter scoring through satisfaction.

Of the control variables, frequency of mall visits has a positive and significant effect on NPS $(\beta=0.093 t=2.25)$, but weekend has no significant effect $(\beta=0.03 t=0.560)$.

\section{Discussion}

This article has the aim of examining the role of stress in retailing by analysing its consequences, its antecedents and its mediating role. Related to the consequences of stress on customer behaviour, two marketing outcomes have been examined: satisfaction and promoter scoring.

Stress is an emotional response that has rarely been included in previous research about customer emotions in the retailing context. The results suggest that stress has no direct effect on promoter scoring because its influence is wholly mediated by satisfaction. Stress decreases promoter scoring by decreasing satisfaction. This finding contradicts general results related to the emotions-loyalty link (Das and Varshneva, 2017; Pons et al., 2016) and the emotions-recommendations link (Jani and Han, 2015; Ladhari, 2007; White and Yu, 2005), although some research has found results that are in line with ours (Lee et al., 2008). Additionally, stress has a negative and direct effect on satisfaction. This result was expected, although it provides new evidence on the negative emotions-satisfaction link. Previous research has focused on the effect of positive emotions such as pleasure and arousal, finding controversial results. For example, Walsh et al. (2011) did not find evidence of the arousalsatisfaction link but they did for the pleasure-satisfaction link. On the other hand, Caro and García (2007) found an arousal-satisfaction link but not a pleasure-satisfaction link. Therefore, our findings provide new evidence on the emotions-satisfaction and emotionsloyalty (or positive recommendation) links by showing that negative emotions such as stress

Table 8.

Mediation effect of stress and satisfaction between disconfirmation of expectations and promoter scoring
Total effect

Direct effect of

IVs

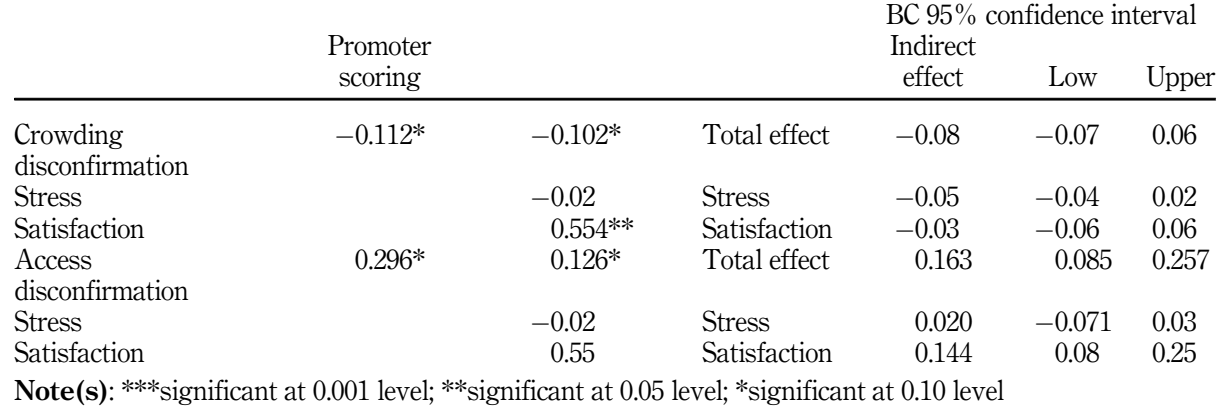


may influence satisfaction in a different way to their influence on loyalty, corroborating previous research (Lee et al., 2008; Das and Varshneva, 2017).

Additionally, this paper also investigated the effects of disconfirmation of expectations as antecedents of stress. According to our results, stress implies individual activation caused by higher crowding perceptions and worse mall accessibility than expected (Baker and Wakefield, 2012; Lucia-Palacios et al., 2018; Machleit et al., 2000). Results relating to disconfirmation of expectations about crowding are like those that consider crowding perceptions; in both cases, findings show a positive influence on stress (Baker and Wakefield, 2012; Eroglu et al., 2005; Hui and Bateson, 1991). Disconfirmation of expectations about crowding has a negative and direct effect on promoter scoring. This aspect also influences customer satisfaction through the generation of stress. With respect to the disconfirmation of expectations about accessibility, our results are in line with those of Hart et al. (2007) who also found that good access to the mall, characterized by fluid traffic and easy navigation inside the mall, leads to a more enjoyable shopping experience. Our results show that good access leads to less stress and has a direct influence on promoter scoring and satisfaction. Mall accessibility seems to be a key aspect of the mall that may help mall managers increase the proportion of promoters among its visitors. This provides us with empirical evidence of the importance of mall accessibility (Hart et al., 2007; Sujan et al., 1999).

Regarding the third objective of this paper, we have found that stress also exerts a partially mediating effect between satisfaction and disconfirmation of expectations about (1) crowding and (2) mall accessibility. However, stress has no mediating effect on promoter scoring. This is because the effect of stress is wholly transmitted through a decrease in customer satisfaction that is a direct antecedent of promoter scoring. These results were partially unexpected as, according to the cognitive-affective model, emotions or customer emotional response should mediate between the stimuli and the customer response. Our findings corroborate those models when satisfaction is analysed as the customer response, which has also been found in previous research (Machleit et al., 2000; Morrison et al., 2011). However, when promoter scoring is the response analysed, the effect of the stimuli is mediated by customer satisfaction with no mediating effect of stress, which is contrary to previous research (Chen et al., 2015; DeWitt et al., 2008; Lucia-Palacios et al., 2020; Jang and Namkung, 2009). Our result is not too controversial as there are previous findings that are in line with ours. For example, Lee et al. (2008) found no mediation effect of negative emotions between stimuli and loyalty, but they found that positive emotions do have a mediating effect.

The present article makes several contributions to research on marketing and retailing. It contributes to the marketing literature by providing more evidence of the role of stress in retailing: its behavioural consequences, some of its antecedents and its mediating role. As consequences of stress, satisfaction and promoter scoring are analysed. Although the outcome of satisfaction has been frequently analysed in marketing research, little is known about promoter scoring. Thus, this article contributes by providing more evidence about the stress-satisfaction and new evidence about the relationship between stress and promoter scoring. Although no emotional response (stress) directly influences promoter scoring, the findings suggest that its effect cannot be undervalued as it is an important cause of customer dissatisfaction.

Finally, while perceptions of the mall environment have attracted attention as antecedents of stress, little is known about the effect of disconfirmation of expectations about the mall environment. This paper provides new evidence about the importance of this aspect to the generation of negative emotions. Therefore, the article contributes by highlighting the role of expectancy-disconfirmations both on stress and on a less common marketing outcome: promoting scoring. The results also provide new evidence of the mediating effect of stress between disconfirmation of expectations and satisfaction. This mediation effect is not exerted on promoter scoring, a relationship not tested previously, so our finding adds to the debate 
about whether there is any type of negative customer emotional response that can directly influence active recommendation or that can act as a mediator.

Thus, this study's results expand on previous research that has found a moderating role of positive emotions in retailing between cognitive stimuli and consumer responses and behaviours.

\subsection{Implications for managers}

Our findings have important implications that are likely to be of interest to mall managers. According to our results, managers should not ignore the stress suffered in relation to crowding and accessibility as this negative emotional response reduces customer satisfaction, and hence promoter scoring. Customers who provide high promoter scoring are characterized by a combination of high levels of satisfaction and their expectations having been exceeded. Therefore, we suggest that managers focus on exceeding customer expectations regarding mall accessibility and ensure that customers experience a lower level of crowding than they expected, as this has a direct impact on satisfaction and active recommendation. Organizing traffic in order to make getting to and leaving the mall easier is a valuable initiative that can improve customers' shopping experience. Therefore, managers should not only help customers access the mall but also inform them about peak hours, so that customers can avoid traffic jams and very crowded environments or at least be prepared for these situations. For that purpose, new technologies or artificial intelligence can be used. Mall managers could create an app to offer information about the level of crowding of the mall and the density of traffic in each access (Al-Sakran, 2015; Khan et al., 2020) to diminish the negative confirmation of expectations about this aspect. Furthermore, mall managers could offer incentives or inform customers about the different ways in which to access the mall, such as by bus, bicycle or public transportation, so as to avoid the use of cars (Brown et al., 2013; East et al., 2017; Fotiadis, 2016). To reduce seasonal variations in the number of visitors, mall managers could organize events during off-peak times or long-term events (for example, events that last for a whole week) to ensure a more stable and equal distribution of visits throughout the week instead of a high proportion of visits on weekends only. Mall managers can reduce perceptions of crowding directly by building wide aisles, increasing lighting, adding vegetation and controlling temperature (Afaq et al., 2020). Furthermore, they can provide customers with services and resting zones where they can relax and have fun, thereby counteracting the stressful effects of crowding (Mehta, 2013; Lucia-Palacios et al., 2020). Mall managers could determine the more crowded areas by using new technologies such as Wifi or GPS tracking, and examining the trajectory and the customer circulation in the mall. They can also influence perceived crowding by changing the circulation layout as suggested by previous research (Park and Zang, 2019).

\subsection{Limitations and further research}

Although this research has several theoretical and empirical implications for mall managers, there are some limitations, as well as recommendations for further research. First, the results and conclusions are obtained from a limited number of observations. Enlarging the sample in future research would enable better generalization of the results. Second, the research has focused on only one customer emotional response. However, other customer emotional responses, both negative and positive, could be examined, such as pleasure, anger or frustration. Future research could also analyse the moderating effect of some situational aspects, such as the day of the mall visit, or of individual traits, such as customer's goals, because these aspects could modify the relationship between satisfaction or promoter scoring and cognitive and affective variables. 


\section{Conclusion}

Stress is an emotional state that can be relevant during the shopping experience at malls. This article demonstrates the negative consequences of stress on customer satisfaction and the NPS measures that are useful for management decisions in shopping centres. Two of the main causes of stress are customers' perceptions of crowding and accessibility. The article investigated the effects of these aspects by considering the differences between shoppers' expectations about crowding and accessibility and their actual perceptions once they have experienced the visit to the mall. The findings show that greater disconfirmation leads to greater stress and diminishes the mall NPS. As a consequence, managers must take into consideration their customers' perceptions of these variables, for instance by providing wide aisles and regulating traffic; they should also manage customer expectations by keeping their customers informed about crowding levels and access possibilities.

\section{References}

Afaq, Z., Gulzar, A. and Aziz, S. (2020), "The effect of atmospheric harmony on re-patronage intention among mall consumers: the mediating role of hedonic value and the moderating role of past experience”, Journal of Consumer Marketing, Vol. 37 No. 5, pp. 547-557.

Albrecht, C.M., Hattula, S. and Lehmann, D.R. (2017), "The relationship between consumer shopping stress and purchase abandonment in task-oriented and recreation-oriented consumers", Journal of the Academy of Marketing Science, Vol. 45 No. 5, pp. 720-740.

Al-Sakran, H.O. (2015), "Intelligent traffic information system based on integration of Internet of Things and Agent technology", International Journal of Advanced Computer Science and Applications (IJACSA), Vol. 6 No. 2, pp. 37-43.

Bagozzi, R.P., Gopinath, M. and Nyer, P.U. (1999), "The role of emotions in marketing", Journal of the Academy of Marketing Science, Vol. 27 No. 2, pp. 184-206.

Baker, J. and Wakefield, K.L. (2012), "How consumer shopping orientation influences perceived crowding, excitement and stress at the mall", Journal of the Academy of Marketing Science, Vol. 40, pp. 791-806.

Bedi, M. (2010), "An integrated framework for service quality, customer satisfaction and behavioral responses in Indian banking industry- A comparison of public and private sector banks", Journal of Service Research, Vol. 10 No. 1, pp. 157-172.

Bendle, N.T., Bagga, C.K. and Nastasoiu, A. (2019), "Forging a stronger academic-practitioner partnership-the case of net promoter score (NPS)", Journal of Marketing Theory and Practice, Vol. 27 No. 2, pp. 210-226.

Bigné, J.E., Mattila, A.S. and Andreu, L. (2008), "The impact of experiential consumption cognitions and emotions on behavioral intentions", Journal of Services Marketing, Vol. 22 No. 4, pp. 303-315.

Brown, A., Kappes, J. and Marks, J. (2013), "Mitigating theme park crowding with incentives and information on mobile devices", Journal of Travel Research, Vol. 52 No. 4, pp. 426-436.

Carmines, E.G. and Zeller, R.A. (1979), Reliability and Validity Assessment, Sage Publications, London.

Caro, L.M. and García, J.A.M. (2007), "Cognitive-affective model of consumer satisfaction. An exploratory study within the framework of a sporting event", Journal of Business Research, Vol. 60 No. 2, pp. 108-114.

Chen, A., Peng, N. and Hung, K.P. (2015), “The effects of luxury restaurant environments on diners' emotions and loyalty: incorporating diner expectations into an extended Mehrabian-Russell model", International Journal of Contemporary Hospitality Management, Vol. 27 No. 2, pp. 236-260.

Dai, H.M., Teo, T., Rappa, N.A. and Huang, F. (2020), "Explaining Chinese university students' continuance learning intention in the MOOC setting: a modified expectation confirmation model perspective", Computers and Education, Vol. 150, p. 103850. 
Das, G. and Varshneya, G. (2017), "Consumer emotions: determinants and outcomes in a shopping mall”, Journal of Retailing and Consumer Services, Vol. 38, pp. 177-185.

De Haan, E., Verhoef, P. and Wiesel, T. (2015), "The predictive ability of different customer feedback metrics for retention", International Journal of Research in Marketing, Vol. 32 No. 2, pp. 195-206.

De Rojas, C. and Camarero, C. (2008), "Visitors' experience, mood and satisfaction in a heritage context: evidence from an interpretation center", Tourism Management, Vol. 29 No. 3, pp. 525-537.

Demoulin, N. and Willems, K. (2019), "Servicescape irritants and customer satisfaction: the moderating role of shopping motives and involvement", Journal of Business Research, Vol. 104, pp. 295-306.

DeWitt, T., Nguyen, D.T. and Marshall, R. (2008), "Exploring customer loyalty following service recovery: the mediating effects of trust and emotions", Journal of Service Research, Vol. 10 No. 3, pp. 269-281.

East, D., Osborne, P., Kemp, S. and Woodfine, T. (2017), “Combining GPS and survey data improves understanding of visitor behaviour", Tourism Management, Vol. 61, pp. 307-320.

Elmashhara, M.G. and Soares, A.M. (2019), "Entertain me, I'll stay longer! The influence of types of entertainment on mall shoppers' emotions and behavior", Journal of Consumer Marketing, Vol. 37 No. 1, pp. 87-98, doi: 10.1108/JCM-03-2019-3129.

Eroglu, S.A., Machleit, K.A. and Barr, T.F. (2005), "Perceived retail crowding and shopping satisfaction: the role of shopping values", Journal of Business Research, Vol. 58 No. 8, pp. 1146-53.

Fierro, J.C., Polo, I.M. and Oliván, F.J.S. (2014), "From dissatisfied customers to evangelists of the firm: a study of the Spanish mobile service sector", BRQ Business Research Quarterly, Vol. 17 No. 3, pp. 191-204.

Fotiadis, A.K. (2016), "Modifying and applying time and cost blocks: the case of E-Da theme park, Kaohsiung, Taiwan”, Tourism Management, Vol. 54, pp. 34-42.

Geisser, S. (1974), "A predictive approach to the random effects model”, Biometrika, Vol. 61 No. 1, pp. 101-107.

Gillison, S. and Reynolds, K. (2018), "Search effort and retail outcomes: the mediating role of search disconfirmation”, Journal of Consumer Marketing, Vol. 35 No. 7, pp. 698-708.

Grzeskowiak, S., Sirgy, M.J., Foscht, T. and Swoboda, B. (2016), "Linking retailing experiences with life satisfaction", International Journal of Retail and Distribution Management, Vol. 44 No. 2, pp. 124-138.

Hair, J.F., Ringle, C.M. and Sarstedt, M. (2015), "PLS-SEM: indeed a silver bullet”, Journal of Marketing Theory and Practice, Vol. 19 No. 2, pp. 139-151, doi: 10.2753/MTP1069-6679190202.

Hampson, D.P. and McGoldrick, P.J. (2017), "Antecedents of consumer price consciousness in a turbulent economy”, International Journal of Consumer Studies, Vol. 41 No. 4, pp. 404-414.

Harris, E.G. and Fleming, D.E. (2017), "The productive service employee: personality, stress, satisfaction and performance", Journal of Services Marketing, Vol. 31 No. 6, pp. 499-511.

Hart, C., Farrell, A.M., Stachow, G., Reed, G. and Cadogan, J.W. (2007), "Enjoyment of the shopping experience: impact on customers' repatronage intentions and gender influence", The Service Industries Journal, Vol. 27 No. 5, pp. 583-604.

Henseler, J., Ringle, C.M. and Sarstedt, M. (2015), “A new criterion for assessing discriminant validity in variance-based structural equation modeling", Journal of the Academy of Marketing Science, Vol. 43 No. 1, pp. 115-135.

Hui, M.K. and Bateson, J.E. (1991), "Perceived control and the effects of crowding and consumer choice on the service experience", Journal of Consumer Research, Vol. 18 No. 2, pp. 174-184.

Ibrahim, M.F. and Ng, C.W. (2002), "Determinants of entertaining shopping experiences and their link to consumer behaviour: case studies of shopping centres in Singapore", Journal of Retail and Leisure Property, Vol. 2 No. 4, pp. 338-357. 
Jang, S.S. and Namkung, Y. (2009), "Perceived quality, emotions, and behavioral intentions: application of an extended Mehrabian-Russell model to restaurants", Journal of Business Research, Vol. 62 No. 4, pp. 451-460.

Jani, D. and Han, H. (2015), "Influence of environmental stimuli on hotel customer emotional loyalty response: testing the moderating effect of the big five personality factors", International Journal of Hospitality Management, Vol. 44, pp. 48-57.

Kaura, V. (2013), "Service convenience, customer satisfaction, and customer loyalty: study of Indian commercial banks", Journal of Global Marketing, Vol. 26 No. 1, pp. 18-27.

Khan, Z., Koubaa, A. and Farman, H. (2020), "Smart route: internet-of-vehicles (IoV)-Based congestion detection and avoidance (IoV-Based CDA) using rerouting planning", Applied Sciences, Vol. 10 No. 13, p. 4541.

Kim, J.H. and Runyan, R. (2011), "Where did all the benches go? The effects of mall kiosks on perceived retail crowding", International Journal of Retail and Distribution Management, Vol. 39 No. 2, pp. 130-143.

Kim, Y.K., Lee, M.Y. and Park, S.H. (2014), "Shopping value orientation: conceptualization and measurement”, Journal of Business Research, Vol. 67 No. 1, pp. 2884-2890.

Knoeferle, K.M., Paus, V.C. and Vossen, A. (2017), "An upbeat crowd: fast in-store music alleviates negative effects of high social density on customers' spending”, Journal of Retailing, Vol. 93 No. 4, pp. 541-549.

Kumar, V., Dalla Pozza, I. and Ganesh, J. (2013), "Revisiting the satisfaction-loyalty relationship: empirical generalizations and directions for future research", Journal of Retailing, Vol. 89 No. 3, pp. 246-262.

Ladhari, R. (2007), "The effect of consumption emotions on satisfaction and word-of-mouth communications", Psychology and Marketing, Vol. 24 No. 12, pp. 1085-1108.

Ladhari (2009), "Service quality, emotional satisfaction, and behavioural intentions: a study in the hotel industry", Managing Service Quality: An International Journal, Vol. 19 No. 3, pp. 308-331.

Lee, Y.K., Lee, C.K., Lee, S.K. and Babin, B.J. (2008), "Festivalscapes and patrons' emotions, satisfaction, and loyalty", Journal of Business Research, Vol. 6 No. 1, pp. 56-64.

Lemke, F., Clark, M. and Wilson, H. (2011), "Customer experience quality: an exploration in business and consumer contexts using repertory grid technique", Journal of the Academy of Marketing Science, Vol. 39 No. 6, pp. 846-869.

Lessassy, L. (2019), "Replacing a delisted brand with premium and standard private labels", International Journal of Retail and Distribution Management, Vol. 47 No. 10, pp. 1057-1073.

Liu, Y. and Jang, S.S. (2009), "The effects of dining atmospherics: an extended Mehrabian-Russell model”, International Journal of Hospitality Management, Vol. 28 No. 4, pp. 494-503.

Liu, F., Lim, E.T., Li, H., Tan, C.W. and Cyr, D. (2020), "Disentangling utilitarian and hedonic consumption behavior in online shopping: an expectation disconfirmation perspective", Information and Management, Vol. 57 No. 3, p. 103199.

Lucia-Palacios, L., Pérez-López, R. and Polo-Redondo, Y. (2016), "Cognitive, affective and behavioural responses in mall experience: a qualitative approach", International Journal of Retail and Distribution Management, Vol. 44 No. 1, pp. 4-21.

Lucia-Palacios, L., Pérez-López, R. and Polo-Redondo, Y. (2018), "Can social support alleviate stress while shopping in crowded retail environments?", Journal of Business Research, Vol. 90, pp. 141-150.

Lucia-Palacios, L., Pérez-López, R. and Polo-Redondo, Y. (2020), "Does stress matter in mall experience and customer satisfaction?”, Journal of Services Marketing, Vol. 34 No. 2, pp. 177-191, doi: 10. 1108/JSM-03-2019-0134.

Machleit, K.A., Eroglu, S.A. and Mantel, S.P. (2000), "Perceived retail crowding and shopping satisfaction: what modifies this relationship?”, Journal of Consumer Psychology, Vol. 9 No. 1, pp. 29-42. 
Maddox, K. (2007), "Research spurs debates over net promoter score”, B to B, Vol. 92 No. 11, pp. 3-33.

Mahmoud, M.A., Hinson, R.E. and Anim, P.A. (2018), "Service innovation and customer satisfaction: the role of customer value creation”, European Journal of Innovation Management, Vol. 21 No. 3, pp. 402-422.

Maier, E. and Wilken, R. (2014), "The impact of stress on consumers' willingness to pay", Psychology and Marketing, Vol. 31 No. 9, pp. 774-785.

Mattila, A.S. and Wirtz, J. (2001), "Congruency of scent and music as a driver of in-store evaluations and behavior", Journal of Retailing, Vol. 77, pp. 273-289.

Mecredy, P., Wright, M.J. and Feetham, P. (2018), “Are promoters valuable customers? An application of the net promoter scale to predict future customer spend", Australasian Marketing Journal (AMJ), Vol. 26 No. 1, pp. 3-9.

Mehrabian, A. and Russell, J.A. (1974), An Approach to Environmental Psychology, MIT Press, Cambridge, MA.

Mehta, R. (2013), "Understanding perceived retail crowding: a critical review and research agenda", Journal of Retailing and Consumer Services, Vol. 20 No. 6, pp. 642-649, doi: 10.1016/j.jretconser. 2013.06.002.

Morrison, M., Gan, S., Dubelaar, C. and Oppewal, H. (2011), "In-store music and aroma influences on shopper behavior and satisfaction", Journal of Business Research, Vol. 64 No. 6, pp. 558-564.

Moschis, G.P. (2007), "Stress and consumer behavior", Journal of the Academy of Marketing Science, Vol. 35, pp. 430-444.

Nunnally, J.C. (1978), Psychometric Theory, McGraw-Hill, New York, NY.

Oliver, R.L. and Westbrook, R.A. (1993), "Cognitive, affective, and attribute bases of the satisfaction response", Journal of Consumer Research, Vol. 20 No. 3, pp. 418-430.

Ou, Y.C. and Verhoef, P.C. (2017), "The impact of positive and negative emotions on loyalty intentions and their interactions with customer equity drivers", Journal of Business Research, Vol. 80, pp. 106-115.

Park, S. and Zhang, S. (2019), "A pilot study of circulation layout based on perceived retail crowding", Journal of Retailing and Consumer Services, Vol. 49, pp. 305-315.

Peng, N., Chen, A. and Hung, K.P. (2017), "The effects of teppanyaki restaurant stimuli on diners' emotions and loyalty", International Journal of Hospitality Management, Vol. 60, pp. 1-12.

Pitt, L.F., Watson, R.T. and Kavan, C.B. (1995), "Service quality: a measure of information systems effectiveness”, MIS Quarterly, Vol. 19 No. 2, pp. 173-187.

Polites, G.L. and Karahanna, E. (2012), "Shackled to the status quo: the inhibiting effects of incumbent system habit, switching costs, and inertia on new system acceptance", MIS Quarterly, Vol. 36 No. 1, pp. 21-42.

Pons, F., Giroux, M., Mourali, M. and Zins, M. (2016), "The relationship between density perceptions and satisfaction in the retail setting: mediation and moderation effects", Journal of Business Research, Vol. 69 No. 2, pp. 1000-1007.

Preacher, K.J. and Hayes, A.F. (2008), "Asymptotic and resampling strategies for assessing and comparing indirect effects in multiple mediator models", Behavior Research Methods, Vol. 40 No. 3, pp. 879-891.

Qazi, A., Tamjidyamcholo, A., Raj, R.G., Hardaker, G. and Standing, C. (2017), “Assessing consumers' satisfaction and expectations through online opinions: expectation and disconfirmation approach", Computers in Human Behavior, Vol. 75, pp. 450-460.

Raassens, N. and Haans, H. (2017), "NPS and online WOM: investigating the relationship between customers' promoter scores and eWOM behavior", Journal of Service Research, Vol. 20 No. 3, pp. 322-334. 
Reichheld, F.F. (2003), “The one number you need to grow”, Harvard Business Review, Vol. 81 No. 12, pp. 46-55.

Reimers, V. and Chao, F. (2014), "The role of convenience in a recreational shopping trip", European Journal of Marketing, Vol. 8 Nos 11/12, pp. 2213-2236.

Rigdon, E.E., Ringle, C.M., Sarstedt, M. and Gudergan, S.P. (2011), "Assessing heterogeneity in customer satisfaction studies: across industry similarities and within industry differences", in Sarstedt, M., Schwaiger, M. and Taylor, C.R. (Eds), Measurement and Research Methods in International Marketing, Emerald Group Publishing, Bradford, Vol. 22, pp. 169-194, Advances in International Marketing.

Ringle, C.M., Sarstedt, M. and Mooi, E.A. (2010), "Response-based Segmentation Using Finite Mixture Partial Least Squares”, Data Mining, Springer, New York, NY, pp. 19-49.

Ringle, C.M., Wende, S. and Becker, J.-M. (2015), SmartPLS 3, Retrieved from, SmartPLS, Bönningstedt, available at: http://www.smartpls.com.

Roozen, I. (2019), "The influence of external design elements on clothing store entry intentions for recreationally and task-oriented female clothing shoppers", The International Review of Retail, Distribution and Consumer Research, Vol. 29 No. 4, pp. 409-429.

Rosenbaum, M.S., Otalora, M.L. and Ramírez, G.C. (2016), "The restorative potential of shopping malls", Journal of Retailing and Consumer Services, Vol. 31, pp. 157-165.

Rychalski, A. and Hudson, S. (2017), "Asymmetric effects of customer emotions on satisfaction and loyalty in a utilitarian service context”, Journal of Business Research, Vol. 71, pp. 84-91.

Saintives, C. and Lunardo, R. (2016), "How guilt affects consumption intention: the role of rumination, emotional support and shame", Journal of Consumer Marketing, Vol. 33 No. 1, pp. 41-51.

Santini, F.D.O., Ladeira, W.J., Sampaio, C.H. and Perin, M.G. (2020), "Effects of perceived retail crowding: a meta-analytic study", The International Review of Retail, Distribution and Consumer Research, Vol. 30 No. 4, pp. 411-436, doi: 10.1080/09593969.2020.1738259.

Sarstedt, M. and Ringle, C.M. (2010), "Treating unobserved heterogeneity in PLS path modeling: a comparison of FIMIX-PLS with different data analysis strategies", Journal of Applied Statistics, Vol. 37 No. 8, pp. 1299-1318.

Singh, S. and Duque, L.C. (2012), "Moderating role of stress in evaluating negative services: encounters with the police", Journal of Service Research, Vol. 15 No. 2, pp. 231-241.

Sivadas, E. and Baker-Prewitt, J.L. (2000), "An examination of the relationship between service quality, customer satisfaction, and store loyalty", International Journal of Retail and Distribution Management, Vol. 28 No. 2, pp. 73-82, doi: 10.1108/09590550010315223.

Smith, R. (2005), "Measuring road rage, conference paper presented at the safety, crime and justice: from data to policy", Australian Institute of Criminology Conference, 6-7 June.

Soars, B. (2009), "Driving sales through shoppers' sense of sound, sight, smell and touch", International Journal of Retail and Distribution Management, Vol. 37 No. 3, pp. 286-298.

Stone, M. (1974), "Cross-validatory choice and assessment of statistical predictions", Journal of the Royal Statistical Society, Vol. 36 No. 2, pp. 111-147.

Sujan, M., Sujan, H., Bettman, J.R. and Verhallen, T.M.M. (1999), "Sources of consumers' stress and stress and their coping strategies", European Advances in Consumer Research, Vol. 4, pp. 182-187.

Swan, J.E.I. and Trawick, F. (1980), "Inferred and perceived disconfirmation in consumer satisfaction. Marketing in the 80's", Proceedings of the AMA Educators' Conference, Chicago, 1980, IL, pp. 97-101.

Uhrich, S. and Tombs, A. (2014), "Retail customers' self-awareness: the deindividuation effects of others", Journal of Business Research, Vol. 67 No. 7, pp. 1439-1446.

Van Dorn, J., Leeflang, P.S.H. and Tijs, M. (2013), "Satisfaction as a predictor of future performance: a replication”, International Journal of Research in Marketing, Vol. 30 No. 3, pp. 314-318. 
Van Ommeren, J., Wentink, D. and Rietveld, P. (2012), "Empirical evidence on cruising for parking", Transportation Research, Vol. 46 No. 1, pp. 123-130.

Van Rompay, T.J., Tanja-Dijkstra, K., Verhoeven, J.W. and van Es, A.F. (2012), "On store design and consumer motivation: spatial control and arousal in the retail context", Environment and Behavior, Vol. 44 No. 6, pp. 800-820.

Walsh, G., Shiu, E., Hassan, L.M., Michaelidou, N. and Beatty, S.E. (2011), "Emotions, storeenvironmental cues, store-choice criteria, and marketing outcomes", Journal of Business Research, Vol. 64 No. 7, pp. 737-744.

Westbrook, R.A. and Oliver, R.L. (1981), "Developing better measures of consumer satisfaction: some preliminary results", in Monroe, K.E. (Ed.), Advances in Consumer Research, Association for Consumer Research, Provo, UT, Vol. 8, pp. 94-99.

White, C. and Yu, Y.T. (2005), "Satisfaction emotions and consumer behavioral intentions", Journal of Services Marketing, Vol. 19 No. 6, pp. 411-420.

Wilson, A., Zeithaml, V.A., Bitner, M.J. and Gremler, D.D. (2012), Services Marketing: Integrating Customer Focus across the Firm, 2nd Europe, McGraw Hill, London. 


\begin{tabular}{|c|c|}
\hline Items & Description \\
\hline \multicolumn{2}{|c|}{ Net Promoter Score (Reichheld, 2003) from 1 to 10} \\
\hline \multicolumn{2}{|c|}{ Can you indicate how likely it is that you would recommend this mall to a friend or colleague? } \\
\hline \multicolumn{2}{|c|}{ Satisfaction } \\
\hline \multicolumn{2}{|c|}{ I have really enjoyed going to the mall } \\
\hline \multicolumn{2}{|c|}{ I am satisfied with my shopping visit in the mall } \\
\hline \multicolumn{2}{|c|}{ Coming to this mall has been a good decision } \\
\hline \multicolumn{2}{|c|}{ Stress (Baker and Wakefield, 2012) } \\
\hline & How often did you experience the following sensations in the mall? \\
\hline ST1 & Frenzy \\
\hline ST2 & Tension \\
\hline ST3 & Anxiety \\
\hline ST4 & Nervousness \\
\hline ST5 & Acceleration \\
\hline \multicolumn{2}{|c|}{ Expectations: I expect that ... / Perceptions: In the mall I perceived that. .. } \\
\hline \multicolumn{2}{|c|}{ Crowding (Baker and Wakefield, 2012; Eroglu et al., 2005; Machleit et al., 2000) } \\
\hline CEC_1 & There were a lot of clients \\
\hline CEC_2 & I felt strained \\
\hline CEC_3 & There were not many people during my visit \\
\hline CEC_4 & It was crowded \\
\hline CEC_5 & I felt constrained \\
\hline CEC_6 & I felt saturated \\
\hline CEC_-7 & It appeared to be an open and airy space \\
\hline CEC_8 & It seemed to me that it was a very spacious place \\
\hline \multicolumn{2}{|c|}{ Accessibility (adapted from Hart et al., 2007; Ibrahim and Ng, 2002; Kim et al., 2014) } \\
\hline CEA_1 & I can move through the mall easily \\
\hline CEA_2 & I can get in/out of the mall quickly \\
\hline CEA_3 & I can get in/out of the mall easily \\
\hline CEA_4 & The mall accesses are not crowded /absence of congestion \\
\hline
\end{tabular}


About the authors

Laura Lucia-Palacios is Assistant Professor in the Department of Marketing at the University of Zaragoza, Zaragoza, Spain. She has published research papers in international journals such as Journal of Business Research, European Journal of Marketing, Journal of Services Marketing, Internet Research and International Entrepreneurship Management Journal among others. Her research interests are focused on customer experience management, new technologies, franchising and pioneering advantages.

Raúl Pérez-López is a PhD student in the Department of Marketing at the University of Zaragoza, Zaragoza, Spain. He has published in international journals such as Journal of Business Research, Journal of Retailing and Consumer Services and Service Business among others. His research interests are focused on consumer behaviour, customer experience management and e-marketing. Raúl PérezLópez is the corresponding author and can be contacted at: raperez@unizar.es

Yolanda Polo-Redondo is Professor in the Department of Marketing at the University of Zaragoza, Zaragoza, Spain. She has published research papers in international journals such as Journal of Service Research, Journal of Interactive Marketing, Industrial Marketing Management and Strategic Management among others. Her main areas of research are strategic marketing, services marketing, customer experience management, and new technologies.

For instructions on how to order reprints of this article, please visit our website: www.emeraldgrouppublishing.com/licensing/reprints.htm Or contact us for further details: permissions@emeraldinsight.com 